Bryn Mawr College

Scholarship, Research, and Creative Work at Bryn Mawr College

2006

\title{
Girl Interrupted: The Queer Time of Warhol's Cinema
}

Homay King

Bryn Mawr College, hking@brynmawr.edu

Let us know how access to this document benefits you.

Follow this and additional works at: http://repository.brynmawr.edu/hart_pubs

Part of the Film and Media Studies Commons

\section{Custom Citation}

King, Homay. "Girl Interrupted: The Queer Time of Warhol's Cinema." Discourse 28, no. 1 (2006): 98-120.

This paper is posted at Scholarship, Research, and Creative Work at Bryn Mawr College. http://repository.brynmawr.edu/hart_pubs/44

For more information, please contact repository@brynmawr.edu. 
King, Homay, "Girl Interrupted," p. 1 of 27

King, Homay, "Girl Interrupted: The Queer Time of Warhol's Cinema," Discourse v. 28, n. 1 (Winter, 2006): 98-120.

Girl Interrupted: The Queer Time of Warhol's Cinema

By Homay King

\section{Coming Attractions}

Warhol made hundreds of Screen Test films between 1964 and 1966. ${ }^{\mathrm{i}}$ The Screen Tests comprise a series of four-minute, silent, black and white portraits, usually shot in head-on closeup, and depict subjects of varying degrees of fame and anonymity, who usually return the camera's gaze with a relatively expressionless fixed stare. Aside from small permutations, the element of greatest variability from test to test is the lighting, which ranges from high-contrast silhouette to washed-out over-exposure. ${ }^{\mathrm{ii}}$ Curiously, Warhol does not seem to evaluate the silent, immobile subjects for any of the abilities or traits that a screen test would normally measure. His subjects barely move or speak. Most of them are posed at a consistent, fixed angle, and the majority of them do not appear in any of his other films. The Screen Tests, it would seem, are "just tests": experiments without results, trial runs that yield no data. The test form has been deteleologized; these films are neither preparatory nor subordinate to a final work. Warhol allows the trial-and-error aesthetic a cinematic life of its own, and the series of Screen Tests remains perpetually open-ended.

Like the Screen Tests, Warhol's Kiss films (1963) are a series of portrait-like shorts. Each Kiss depicts a different couple engaged in an embrace, in various combinations of gender and ethnicity. The films are silent and of a uniform, four-minute duration, with all but one filmed in static close-up and demonstrating only slight variations in angle and distance. The fact that the Kisses were at one time exhibited as individual shorts prior to feature presentations at the Filmmakers Co-op in New York, as if they were trailers, aligns them yet further with the Screen 
King, Homay, "Girl Interrupted," p. 2 of 27

Tests. ${ }^{\text {iii }}$ This mode of exhibition suggests that, like the Screen Tests, the Kiss films engage in something like cinematic foreplay. Both the Screen Tests and the Kisses offer situations where what is normally considered preliminary, anterior to, and outside the real work becomes the main attraction. Precursory activities become feature events; the "test" and the "trailer" are elevated to the status of complete projects. These films practice an introductory, anticipatory form of cinema in which a simulation or rehearsal is taken just as seriously as the final result.

The Kisses and Screen Tests are but preliminary examples (both in Warhol's filmic oeuvre and in this essay) of what I will describe as the queer temporality of Warhol's cinema. Douglas Crimp, Thomas Waugh and others have noted that scholars of the American 1960s avant-garde have frequently, in certain instances deliberately, overlooked the queer aspects of Warhol's oeuvre. ${ }^{\text {iv }}$ What Waugh calls "formalist disavowals of the primacy of sexual representation," offered by "critics of the modernist, postmodernist, or heterosexist persuasion," as Waugh describes them, "routinely fail to mention that the male in Sleep is nude, and somehow forget that Haircut and Horse include a slow male striptease and a cowboy strip poker game, respectively." Recent scholarship has contributed much to the deconstruction of this binary opposition between the "formalist Warhol" and the "queer Warhol," and has revealed that the formally attentive reading need not be made at the expense of the culturally or historically attentive one and vice versa. ${ }^{\mathrm{vi}}$ One could also note that this division is one that postdates the era of Warhol's own productivity: early scholarship on Warhol's films by critics such as Parker Tyler and Gregory Battcock remains among the most formally rigorous, while offering some of the most sophisticated readings of the films' sexual politics. Still, this binarism persists, particularly in the way his films are often divided up between those considered landmarks of 
King, Homay, "Girl Interrupted,” p. 3 of 27 conceptual innovation (Empire) and those that are implicitly taken to be of lesser artistic quality (My Hustler).

This essay aims further to bridge the divide between formalist and queer readings of Warhol's films, not through recourse to biography or figuration, but through an analysis of the queer temporality of Warhol's cinema. Waugh suggests that "gay" narratives partake of a different kind of temporality than do "straight" ones, and while his definition is broad, it provides a useful starting point. "Gay narratives," Waugh writes, "for the most part posit separation, loss, displacement, endless deferral, and open endings" in place of unification, identity, fulfillment and closure (Waugh, 57). This description anticipates what Judith Halberstam has more recently described as "queer temporality": temporal forms that are nonteleological and non-purposeful, and that critique the normative timetables of heritage, kinship, and reproduction, as well as the standardized clock-time of labor and leisure. ${ }^{\text {vii }}$ In "Dragtime and Drugtime, Or, Film à la Warhol," Parker Tyler likewise describes two types of aberrant temporality in Warhol's films that, while not precisely queer, go against the conventional temporality of film spectatorship. viii "Dragtime," for Tyler, is “eventless" (Tyler, 31) and “nonprogressive" (Tyler, 88); it may resemble a "vicious circle" (Tyler, 30) or "an endurance test" (Tyler, 87). "Drugtime," on the other hand, is "the time of sublimated leisure: all the time in the world" (Tyler, 87); it resembles not a teleological journey, but rather a psychedelic "trip" (Tyler, 88). Tyler suggests that these two temporal modes are frequently to be found together, in oscillation with one another, in Warhol's films. In Blow Job, the narrative "event" and suspense of fellatio are undercut, for the film gives primacy not to sexual fulfillment and closure, but rather to an infinitely extended fore-pleasure (drugtime). At the same time, the film highlights the physical labor and even boredom that seem to accompany this act (dragtime). Tyler's 
King, Homay, “Girl Interrupted,” p. 4 of 27 description of dragtime is related to what Elizabeth Freeman calls "temporal drag:" a "retrogression, delay, and pull of the past upon the present."ix This pull of the past on the present, the elongation of time beyond the parameters of the clock, has a formal equivalent in Warhol's silent films that were meant to be projected at the protracted rate of sixteen frames per second (Kiss and the Screen Tests among them).

In this essay, I explore these and similar manifestations of queer temporality in four films, the first three of which all feature Edie Sedgwick: Poor Little Rich Girl (1965), Restaurant (1965), and Kitchen (1965). The Edie Sedgwick films provide a fraught yet extremely generative starting point for a queer and feminist reading of Warhol's cinema. Of the Sedgwick films, Outer and Inner Space (1965) has received perhaps the most critical attention: its split-screen, videowithin-film mise-en-abyme structure permits a wide range of formal, historical, and theoretical interpretations. ${ }^{\mathrm{x}}$ Other films from this group — Poor Little Rich Girl, Restaurant, and Kitchen, as well as Afternoon (1965), Beauty \#2 (1965), Space (1965), and Lupe (1965) — have been critically overshadowed to an extent by other works, both more sensational (Chelsea Girls) and less (Sleep). However, the Sedgwick films permit equally compelling analysis, and additionally offer an opportunity to reconcile queer Warhol scholarship both with feminist critiques and with more formalist approaches to his oeuvre. The essay concludes with a section about Warhol's Sunset (1967), a film that also disrupts conventional cinematic temporality, and that features another of Warhol's female stars, Nico, speaking in voice-over. Although none but Kitchen feature explicitly homoerotic content, these four films could be described as participating in a queer temporality. They could also be described as perverse, in the non-pathological sense that Freud alludes to in Three Essays on the Theory of Sexuality: that is, they "linger" over moments that cannot be assimilated to teleological or goal-oriented action. ${ }^{\text {xi }}$ Like the Kisses and Screen 
King, Homay, "Girl Interrupted," p. 5 of 27

Tests, these films make activities that fall outside the logic and temporal progression of heterosexual reproduction into ends or works in their own right. Like an infinitely extended kiss, Warhol's films tend to be about the prelude rather than the finale, and they invite us to experience the thrill of anticipation without fulfillment. The visual pleasure they offer is predicated not on narrative progress, but on the enjoyment of temporal disjuncture. Their temporality has to do with the not-yet time of interstitial modes of being, the waiting time of a potentiality without closure, and the too-soon time of objects not yet ready to expire. Warhol's temporal aesthetic invites permutation and proliferation, all while critiquing and troubling conventional notions of reproduction as they pertain to sexuality and representation.

\section{Beginning: Poor Little Rich Girl (1965)}

Poor Little Rich Girl is a two-reel sound film starring Edie Sedgwick, the first that Warhol made with her. Shot in Sedgwick's apartment, the film was originally to be the first section of a longer project of the same title, documenting a day in the life of Warhol's first superstar. The first image we see is an extremely blurred close-up of Sedgwick's tilted head, so poorly focused as to be almost indecipherable. ${ }^{\text {xii }}$ The first reel is taken from an occasion when two rolls of film were accidentally shot out of focus; Warhol later shot two more reels in focus and purposely selected one reel from each shoot for the final version of the film. At first, the camera remains in a fixed shot of Sedgwick's head, which occasionally moves outside the frame. As the camera starts to move, we begin to make out a few actions through the poor focus: Edie sitting on her couch, doing leg lifts, bobbing her head to the music of Bob Dylan and the Everly Brothers on a record player. Throughout the first reel, however, the lack of focus creates a hazy, ghostly effect. The poor sound quality further complicates attempts to determine what is taking 
King, Homay, "Girl Interrupted,” p. 6 of 27

place in the frame, although at times it provides a clearer indicator than the visual image: like many of Warhol's films from this period, Poor Little Rich Girl begins with a verbal announcement of its title, spoken by an off-screen Chuck Wein; this title is borrowed from a 1936 film by Irving Cummings starring Shirley Temple, of whom Warhol was a devoted childhood fan. ${ }^{\text {xii }}$ The earlier Poor Little Rich Girl tells the story of a young girl who is catapulted into radio soap-opera stardom because of her inability to distinguish between fantasy and reality: Temple's character gets lost on the way to boarding school and is subsequently taken in by a couple of vaudeville performers, thinking all the while that she is merely engaging in an elaborate role-play (one could argue for an oblique parallel to Sedgwick's role in the Warhol factory).

The second reel of the film corrects the blurred focus of the first, and calls attention to this change with a well-lit, high-contrast image in sharp focus. In the first distinct line of dialogue in this reel, Sedgwick addresses Wein, who is still off-screen: "Chuck? Are you going to wake up?" Presumably he has fallen asleep on the set, or has failed to respond to a remark she has made. But the question also comments on the "waking up" of the film from the unfocused slumber of the previous reel. Other bits of dialogue and activities from the second reel thematize the idea of waking up: Sedgwick startled by the telephone ringing, getting dressed and trying on different outfits, putting on make-up at her vanity table as if preparing to go out, and taking a combination of pills. During the first reel of the film, we also hear the songs "All I Have to Do Is Dream" and "Wake Up Little Susie," which tells a story of waking up at four o'clock in the morning (Sedgwick, as we learn from a bit of dialogue, has woken up at four o'clock in the afternoon). The song predates the film by seven years, and is from a retrospective album entitled The Very Best of the Everly Brothers. It thus participates in what Freeman calls "drag" 
King, Homay, "Girl Interrupted," p. 7 of 27 temporality: the pull of the past upon the present. The film also "drags" in Tyler's sense, in that its poor focus and relative eventlessness demand effort and patience from the spectator.

Warhol later wrote that the films he made with Sedgwick "had more of a pajama-party atmosphere than anything else" (POPism, p. 109). Poor Little Rich Girl seems to comprise an oblique companion piece to Warhol's earlier and more infamous Sleep (1963). If so, it is a sequel to Sleep that comes chronologically afterwards, but that is nevertheless about beginnings. Sedgwick's blurry transition to a waking state takes place over the course of an extended morning that encroaches far into the day. In this sense, Poor Little Rich Girl also suggests a connection to what David James calls the "amateur" aspects of Warhol's cinema. ${ }^{\text {xiv }}$ The term amateur suggests not only one who admits of technical imperfection, but also one who practices out of love, and who is a beginner. Poor Little Rich Girl not only occupies an early place in Warhol's filmic oeuvre (especially with regard to his use of the Auricon camera); it also thematizes the affect of beginning.

In In a Queer Time and Place: Transgender Bodies, Subcultural Lives, Judith Halberstam defines queer time as "those specific models of temporality that emerge within postmodernism once one leaves the temporal frames of bourgeois reproduction and family, longevity, risk/safety, and inheritance" (Halberstam, 6). Queer temporality, Halberstam notes, exploits what Baudelaire calls "the transient, the fleeting, the contingent" (Halberstam, 6). It is opposed to the qualities that, in The Condition of Postmodernity, David Harvey associates with late capitalism: the carving out of distinct spheres of "industrial time," "family time," and "leisure time," and the reification of these temporal modes such that they appear as given rather than as effects of a socio-economic regime (Halberstam, 7). Halberstam offers Beckett's Waiting for Godot as a text that critiques this reification of time. When we realize that the characters are waiting for nothing, 
King, Homay, "Girl Interrupted," p. 8 of 27 that "nothing has been postponed and nothing will be resumed," Halberstam says, "the experience of duration makes visible the formlessness of time" (Halberstam, 7). That formlessness is opposed to the rigid timetables: laboring hours, schedules for marriage and childbearing, and the "generational time" that links families to nationalistic discourses of history and progress. These timetables are naturalized, biologized, and enforced by legal, economic, and social pressures and incentives from the state. The fact that deviations from such timetables are pathologized to such an extent — nocturnal labor or diurnal rest are read as signs of depression; childlessness is taken to indicate physical illness or developmental regression — reveals their ideological construction, and speaks to the profound anxiety and perceived threat to the social order that arises when individuals fail to keep to the prescribed schedule.

The subject matter and time of day in Poor Little Rich Girl invoke a kind of time that is exempt from such schedules. Sedgwick appears to be enjoying a window of late-adolescent freedom from the demands of work and family that, if not precisely queer, is clearly out of synch with capitalism's usual schedule. Her class position, as the heiress of a wealthy New England family, is precisely what permits this window: it is the result of generational, patrimonial time. But the film also suggests that Warhol's fascination with money is in fact a fascination with deviant temporality, with money's power to free its bearers from hetero-normative time. The film's aesthetic also participates in a queer temporality. The lack of editing, common in Warhol's filmic oeuvre, favors temporal formlessness and transient movements over landmark events, as does the film's two-reel structure. Granted, it is possible to read the two reels in terms of a narrative "before" and "after" — the blurred reel's sleep as preface to a focused awakening, or the fuzzy contours of a girlish, pre-lapsarian phase followed by the clarity and knowledge of reel two. We might also be tempted to ascribe qualitative judgments to the two reels, labeling the 
King, Homay, "Girl Interrupted," p. 9 of 27 blurred exposure as a "poor" image and the focused one as "rich." However, the reels do not belong in a rigid chronology. Like several of Warhol's multi-reel films, they have been projected both in sequence and synchronously, side-by-side. We can thus read Poor Little Rich Girl as a film that takes us beyond the dichotomies of pre versus post, unfinished versus polished. The blurred and focused images are on the same playing field: first and second filming attempts, degrees of visual resolution, failure and success resist assimilation to rigid chronologies and hierarchy. If we attempt to read the first image as one of innocence, we are confronted with its status as botched, ruined exposure: it is "spoiled," much like Sedgwick herself, whose upperclass status Warhol seems both to worship and to expose. ${ }^{\mathrm{xv}}$ The film invites us to leave behind both narrative chronology and formal evaluation in favor of in-betweenness and the not-yet.

Poor Little Rich Girl is a portrait of an interstitial figure. Sedgwick's androgynous gendering — her visual similarity to Warhol, with their twin silver hairdos and sartorial styles likewise evokes an in-between quality. ${ }^{\text {xvi }}$ Her age, twenty-two at the time of filming, suggests a time on the brink between adolescence and early adulthood. As Freeman suggests in "Packing History," the term "girl" evokes "an embarrassing past as the crucial augur of a critical, yet also contingent future," and suggests the "promising distortions...of sexual and gendered personhood" that may arise when this shadowy past is permitted to erupt into the present (Freeman, 741). True, "girlhood" suggests a pejorative cusp: not so much the unbridled riotousness of pre-Oedipal sexuality as the latency phase, a time of erotic repression, social conformism, and incapacity. However, as Freeman suggests, girlhood also promises new transformations and future contingencies. Poor Little Rich Girl insists on this temporal interstice, occupying it with a curiously active approach to inactivity that is apparent both in Sedgwick's busy way of moving and in the camera's pulsing, agitated zooms. Warhol's fascination with his 
King, Homay, "Girl Interrupted," p. 10 of 27

subject in this film seems to stem not only from her symbolic position as society debutante, but from the enthusiastic way she inhabits the amorphous temporality that this position allows. Sedgwick's sister once described her as "a perverse Peter Pan," an epithet that evokes both androgyny and a refusal of adulthood and its developmental progresses. ${ }^{\text {xvii }}$ Poor Little Rich Girl relishes the hazy time that results from this refusal.

Waiting: Restaurant (1965)

Restaurant (1965) begins with a black screen, created by a hand placed over the camera lens. This shot is followed by a quick, in-camera cut. A man with his back to the camera occupies the bulk of the image, and at his right we see a white statue of a human figure. A light flashes briefly, and another quick cut reveals a medium shot of a vacant table in what now appears to be a restaurant, with the statue still at the right side of the frame alongside a smaller table. The third and final in-camera cut of this opening sequence brings us to a close-up on the center table, which is arrayed with white napkins, a metal decorative lamp, a triangular ashtray, a straw-covered bottle of Chianti, and a stemmed Tom Collins glass. A single bread plate sits at the foreground of the table, with a white napkin and silverware next to it. The table is framed in a manner that strongly suggests a Dutch still life painting: the objects are arranged with a studied casualness, appealingly lit and invitingly proximate. At this point in the film, we may imagine that Warhol's film was titled not only for its setting, but for the etymological origins of the word "restaurant," "to restore." There is a sense of return — to painting, to stillness, to inanimate objects.

The camera remains in this fixed shot for approximately the first half of the reel. Hands move in and out of the frame as guests begin to arrive at the restaurant, but we do not see faces 
King, Homay, “Girl Interrupted,” p. 11 of 27 or other body parts until later in the film. We can thus decipher the action only from the movement of the hands that shift glasses, handbags, and cigarettes around the table. The soundtrack provides other clues; we hear screams and greetings as more guests arrive. The primary topic of conversation in this portion of the film concerns missing guests, wondering where they are and anticipating their arrival. Sedgwick, who plays a featured role, asks where Chuck Wein is, comments that Ondine has just gotten back from the Panama Canal, and asserts that she would go to Tangier with the others if she could. ${ }^{\text {xiii }}$ The question "where" seems to be the paramount one for both the patrons of the restaurant and the spectator. We cannot see beyond the close-up of the table, and although we know that the guests are seated nearby, they remain invisible. ${ }^{\text {xix }}$ Despite our proximity to the table, we remain disconnected from the action, and the close, fixed framing thus creates a distancing effect similar to that of the blurred focus in Poor Little Rich Girl.

After about ten minutes, the camera begins a protracted, almost imperceptible zoom out from the fixed still life composition. It gradually reveals the people seated at the table. Warhol finally settles on a medium shot of the entire table and the six guests seated there, and then begins to pan slowly around, occasionally pausing at particular framings. This type of camera movement, followed by brief fixed images, continues throughout the rest of reel one and for the entirety of reel two. In contrast to the fixed, still shot of the table, the frame has become a liquid space where no particular objects are foregrounded. However, Warhol does allow us to decipher certain events. Towards the end of the first reel, after the camera has started to move, Sedgwick impatiently asks, "Where's the food? We've been here at least an hour!" The remark is comical: we know that the guests have only been at the restaurant for about twenty minutes, because the camera has been rolling the entire time. We soon realize that, in this film, the question "where?" 
King, Homay, “Girl Interrupted,” p. 12 of 27 applies as much to the food as to the guests. Not much eating happens at this restaurant; the main activity seems to be waiting. When the waiter finally does arrive — having not so much waited upon his guests as made them to wait — he presents a whole, uncooked eggplant and an enormous pineapple, which the guests examine quizzically. Like Warhol's soup cans and Coke bottles, they are more like iconic renditions of food than actual nourishment, signifiers that are marked as representational rather than objects available for consumption. They also recall the theme of travel to faraway places, suggested earlier by the conversations about Panama and Tangier.

The Golden Age-era Dutch still life assembles goods collected from various exotic places into a single frame. ${ }^{\mathrm{xx}}$ It also takes objects out of their temporal context, situating blossoms, ripe fruit, and decaying produce alongside one another, making contemporaries of them all. In its traditional form, the still life genre offers up objects for consumption, appraisal, and ownership. It also showcases the ability to overcome geographical distances and seasonal rhythms, space and time. The genre works to achieve mastery over them through representation, and trumpets the political and economic conquests that make this overcoming and abundance possible. However, just as Poor Little Rich Girl undoes the logic of normative developmental time, so Restaurant undoes the temporal logic of capitalistic growth. It does so in a way perhaps only possible in a time-based medium: by emphasizing duration over instantaneous rewards and profit, and by emphasizing waiting time over completed accumulation and consumption. We come to understand that the title "restaurant" refers less to a restoration of past forms than to the rest as pause or break, as well as to the notion of "the rest" in the sense of the incomplete, the deficit, the remainder, and what resists incorporation into the whole. 
King, Homay, "Girl Interrupted," p. 13 of 27

Restaurant is in many ways an eventless film. The arrivals and departures — of guests, waiters, and food - feel anticlimactic, and even go unnoticed by the camera. When the camera finally begins to move, another suspenseful moment for which the spectator waits, this, too, has the feeling of anti-climax. Rather than remaining with our protagonists, Warhol's camera strays around the edges of the group and wanders off to other tables, in one case meandering inexplicably, even perversely, to a woman's oversized print hat, where it remains in contemplation for a good deal of time. The camera's slow pans and erratic zooms in and out, characteristic of Warhol's filming style, suggest a non-teleological movement. This style of movement opposes both the conventions of the still life genre of painting and those of classical narrative cinema that require space and time to be subordinated and cut to the measure of purposeful narrative action. ${ }^{\text {xxi }}$ The film crawls along in that mode of endless deferral that Waugh associates with gay narrative, and that Tyler links to dragtime. It thwarts the dialectic of concealment and revelation that we may have come to expect from its opening. Halberstam says of Waiting for Godot, that "nothing has been postponed and nothing will be resumed" (Halberstam, 7); the same seems true of Restaurant. It undoes the temporal structure of anticipation and discharge, leaving us waiting for a party that never happens, whose guests are still at the table after the camera roll runs out.

Interrupting: Kitchen (1965)

Kitchen (1965) could be seen as a kind of companion piece to Restaurant with some key differences. Whereas Restaurant imports materials from the world of high art into the popular medium of low-tech cinema, Kitchen could be said to elevate outcast materials to the status of finished film. Whereas Restaurant is only loosely narrative in form, Kitchen is a film with a 
King, Homay, “Girl Interrupted,” p. 14 of 27

script by Ronald Tavel. Kitchen's scenario involves a young couple named Mikie (Roger

Trudeau) and Jo (Edie Sedgwick) sitting in their kitchen, discussing marital difficulties. Throughout the film, a houseboy (René Ricard) busies himself in the background and a photographer (David McCabe) moves about and snaps pictures - sometimes the other characters pose for the photographer, but more often they ignore him. ${ }^{\text {xii }}$ Halfway through the film, in the second reel, another couple named Mikey (Elektrah Lobel) and Joe (Donald Lyons), whose names are homonyms of the first couple's, arrive and create confusion. The second couple reverses the genders of the first (Mikie is a man, and Mikey a woman; Jo a woman, and Joe a man). The male Mikie, we learn, has recently had an affair with the male Joe at the public baths. Occasionally a malted machine is turned on and makes a deafening noise, preventing both the spectator and the actors from hearing the dialogue. Jo \#1 is frequently overcome by sneezing fits, which further interrupt the action and interfere with the speaking and hearing of lines. The film culminates with the dramatic dénouement of Jo \#1's murder by her husband. After briefly posing in the murder tableau, the actors get up and begin to mill about. The script has ended, but Warhol's camera roll has not yet run out: the remainder of the film continues to show this postproduction phase, as the actors look into the refrigerator and begin to clean up the set.

Kitchen is ostensibly a film about a couple experiencing marital woes in an emotionally claustrophobia domestic space, and in this sense, it loosely invokes the scenario of the Hollywood melodrama. ${ }^{\text {xiii }}$ The manner of filming complements the repressive feeling with its closed composition: the flattened depth of field, crowded mise-en-scène, and frame edges blocked by furniture and appliances all contribute to the sense that there is no escape from this domestic interior. ${ }^{\text {xiv }}$ However all of this is complicated by the arrival of the second couple, who are like discarded doubles of the first. Mikey and Joe would seem to function as repressed male 
King, Homay, "Girl Interrupted," p. 15 of 27

and female counterparts — psychical out-takes — who return to disrupt the sterile marriage, ultimately shattering it with the murder of the first Jo. We have a kind of unmasking of heterosexual domesticity and kinship. That is, the new Joe and Mikey reveal the trashed repressions upon which conventional structures of heterosexuality are based. The film does not merely parody or send up gender differences and the heterosexual couple; rather, it anarchizes these differences, rendering them indeterminate by multiplying their emissaries.

As in other films from the Warhol-Tavel collaboration, an off-screen voice reads the film's opening credits aloud: "Reel One of Andy Warhol's Kitchen. Alternate titles: 'Half an Ass,' 'Illusion,' 'Vacuum.'” The inclusion of the alternate titles makes the theme of multiplicity evident from the start, and presages the arrival of the alternate Mikey and Joe. The voice continues, and, after crediting the actors, begins to read the list of props, which include a kitchen table and chairs, books, pencil, mascara equipment, mirror, litter basket, a choker, a malted machine, and a can of shoe spray. The phrase "everything but the kitchen sink" comes to mind, and indeed, practically every object in the room is duly named and credited (including the kitchen sink). We are soon told that some of these objects have an important role to play in the film's execution. The off-screen voice continues thus:

One wall of the kitchen is in frame and a calendar is on that wall, which is not actually a calendar but a copy of the scenario. Several articles are on the table and hidden between them is another copy of the scenario. There is also a large book on the table, or two or three books, and copies of the scenario are hidden in the books. When the actors forget their lines, they should pretend to be reading the book, or can get up and go over to the calendar on the wall and read until they reach the place they want as if they were tearing off back dates. ${ }^{x x v}$ 
King, Homay, "Girl Interrupted," p. 16 of 27 At no time during the film do any of the actors visibly rifle through the book or go over to the calendar to check the script, although there are a number of times when they seem to have forgotten their lines (Mikie repeats certain phrases to Jo in an emphatic tone "Do you understand, Jo? I said, do you understand, Jo? — as if cueing her to say a dropped line). ${ }^{\text {xxi }}$ In failing to consult the script, the actors show themselves to be in opposition to the off-screen voice-over. To resort to the calendar, as it instructs them to do, would be to succumb to the very sign and instrument of regulated time, normative work and leisure time, chronological and teleological time, all of which run counter to the film's own queer temporality. Forgetting and interrupting trump the function of the calendar to remind and hurry the program along.

A similar voice-over prefaces the second reel of the film, and the arrival of the new actors creates yet further ambiguity surrounding the delivery of lines. Sedgwick's Jo seems to register this confusion more acutely than the others, and during one of the many disruptive blasts of noise from the malted machine, she breaks character and remarks,

I just can't stand the sound of that awful machine. I mean, you just can't hear what you're saying with that machine grinding away like that. I mean, you can't hear what I'm saying...I can't hear what I'm thinking!

Similar breakdowns occur throughout the second reel. Joe remarks, as if by way of apology, "I'm only playing my part.” Jo retorts, “I play my parts too, only I can’t figure out what my part is in this movie!"xxvii She soon turns to Mikey, and asks, "What did you say your name was? That mixes me up, because his name is Mikie too." ${ }^{\text {xxviii }}$ Here, Sedgwick seems to be both the star of the film and its least prepared actor. Towards the end of the film, Mikie strangles Jo and leaves her lying on the kitchen table. Her murder seems to arrive as a punishment not only for her 
King, Homay, "Girl Interrupted," p. 17 of 27 marital transgressions, but also for breaking character and failing to "play her part." She transgresses both the domestic space of home and marriage and the space of the diegesis, into which erupts what is supposed to remain behind the scenes.

Indeed, Kitchen is what we could call a "behind-the-scenes" film in several senses. A kitchen is a place where things are prepared, a sort of back-stage to a dining room or restaurant. Likewise, Warhol's Kitchen consistently reveals the preparatory and occluded stages of filmmaking. Actors seem unready to play their roles, and deliver their lines as if the shoot were only a rehearsal. Jo spends a great deal of the sixty-six minute film sitting on a stool with her feet on a chair, wearing only a striped t-shirt and dancer's tights, putting on endless quantities of mascara, as if she were preparing herself to go on camera rather than already in its full view. Matthew Tinkcom notes that films such as Haircut (No. 1), Poor Little Rich Girl, and Camp "situate the men and women who appear in them in terms of how much these subjects must work to make themselves ready for the camera." ${ }^{\text {xxix }}$ In Kitchen, this sense of laboring contributes to the "dragtime" pole of that oscillating temporal space Tyler identifies in Warhol's films, between the lagging delay on the one hand and the trippy expansions on the other. While Edie paints her face, the house boy spends the bulk of the film busily moving around the set, carrying boxes back and forth and sweeping the floor, and the stills photographer snaps about. It is as if they were preparing the set for the film instead of already acting in it. Kitchen is a film that has started too early, before its actors are prepared to go on. In this sense, its temporality is analogous to that which Freud describes as characterizing the onset of sexuality, a traumatic implantation that arrives before the subject is fully equipped to handle and interpret it. ${ }^{\mathrm{xxx}}$

A similarly disjunctive pacing and dramatic example of "too-early" temporality occurs at the end of the film, when the actors finish the script before Warhol's camera has run out of film. 
King, Homay, “Girl Interrupted,” p. 18 of 27 After Jo's murder, the actors remain posed in a tableau around the table for a few seconds, then abruptly leave their posts and begin to mill about. At this point, several crew members enter the frame and being to clean up and look into the refrigerator, asking if there is any beer left. Although the narrative has ended, the camera continues to film the aftermath of the pro-filmic event as Warhol adheres to his principle of using an entire camera roll of film without editing. The wrap stage of the shoot is not separated from the performance. Both phases occur within the diegesis of the film, and assume an equal importance with regard to the immobile camera, occurring within an identical frame and with no formal markers to distinguish them. Sedgwick says, "Too fast! When is it over?" She then shows off a burnt finger, a casualty of the filmmaking process: "I didn’t realize I got burnt before. Jesus God! Look at it." The burnt finger is like a less extreme version of the killing. Just as Jo is martyred for her transgressions within the story-space of the film, so Edie is punished for rushing in the aftermath of the story.

Kitchen reveals what goes on behind the scenes, exposes the dirt and messiness, what is normally supposed to be hidden from view in the final presentation, the "out-takes" with which Warhol supplies the filmic apparatus. The lack of differentiation in the film among rehearsal, play, and clean-up or wrap can be viewed in this way. Some segments of dialogue address the notion of the "out-take" through the theme of trash (a hair deliberately stuck in the lens and printed onto the film emulsion serves as a constant reminder of this). In a conversation from the first reel between the original Mikie and Jo:

Mikie: Why did you throw my undergarments into the litter basket?

Jo: They were mildewed, dear.

The argument about litter reflects a larger concern over the fate of ephemeral objects, and later in this conversation, Jo says to Mikie, "You're right. Half the things in the litter basket shouldn't 
King, Homay, “Girl Interrupted,” p. 19 of 27 have been thrown out." Just as the actors have finished the script too fast, so the items in the litter basket have been made to expire too soon. Gregory Battcock notes that objects in Warhol's Kitchen "gain new importance," but are at the same time "no longer 'permanent' in the way that art could once be said to be... New books, better recordings, and new art will and must replace [the old] and accommodation for the replacements is built in ahead of time" (Battcock, 47). The litter basket conversation in Kitchen indeed foregrounds the disposability not only of everyday objects, but of transitory new artistic media and modes of reception that render the work of art prematurely obsolete, as if it were an ordinary commodity. As Jonas Mekas notes, "Warhol seems to have incorporated all the transitoriness of things into his very aesthetics...His cinema is really about the transitoriness of the medium."xxxi Mekas' remark suggests a critique of the film industry, in that half of what the film industry discards does not actually belong in the trash and can still be put to good use. Warhol's lack of editing in the 1965 films and others that used entire reels of raw footage (including the "botched" reel of Poor Little Rich Girl) attests to an ethical practice of "using the whole animal" in his films.

The use of recycled and out-take bits of film refuses late capitalism's impulse toward premature obsolescence. Like Warhol's insistence on using up his entire roll of film, his saving of ephemera, and his documentation of even the most minor expenses, this practice could be described as part of an environmentalist sensibility, as evidence of a compulsive inability to throw anything away, or both. Warhol claimed that he "always like[d] to work on the leftovers, doing the leftover things. Things that were discarded, that everybody knew were no good, I always thought had a great potential to be funny. It was like recycling work."xxxii Returning to the notion of queer temporality provides another way to think about these practices. In particular, Freeman's notion of dragtime can be linked to recycling, which finds creative possibilities in old, 
King, Homay, "Girl Interrupted," p. 20 of 27 out-moded, or overly familiar materials. Warhol's aesthetic, as we know, was based largely on the appropriation, re-use, and transformation of public images, and their repetition in serial form with minor yet crucial variations. Although this aesthetic is less obvious in the films than in the silk screens, his cinema shares with the silk screens a multiple, serial form (as in the Kisses, Screen Tests, and other numbered films like Haircut), and an element of variability (as with the variations among the films in series, and the multi-reel films that could be projected in different ways). Some have also argued that the films rely on appropriation, albeit of non-public materials, as much as do the silk screens. ${ }^{\text {xxiii }}$ Whether we choose to ascribe political meaning or not to Warhol's practices of re-use and recycling, clearly they embody a principle of renewability, of sustainable artistic production with tremendously prolific results.

It is important to emphasize, though, that this generative structure is not tied to a capitalistic narrative of accumulation and progress, nor to the biological imperative of heterosexual reproduction. In Kitchen, Warhol's resuscitation of discarded materials and outtakes suggests a critique of capitalism's wastes. The send-up of the domestic melodrama and gender- and sexuality-bending characters clearly suggest something queer, and something outside hetero-normative structures of kinship and reproductive. The film's queer temporality marks it as part of a larger project within Warhol's oeuvre in which both Poor Little Rich Girl and Restaurant share, and which I have been arguing is present even in those films that lack explicitly queer content. With its too-early beginning and too-soon ending, its constant interruptions and deferrals, and its characters who loiter around long past the film's conclusion, Kitchen presents a panoply of aberrant temporal forms that resist the normative timetables, both economic and familial, that tend to dominate and structure late capitalist subjectivity as well as its narrative cinematic forms. 
King, Homay, “Girl Interrupted,” p. 21 of 27

Not Finishing: Sunset (1967)

I conclude this essay with an analysis of Sunset, a film that represents a different stage in Warhol's filmmaking than the three 1965 two-reel films I have just discussed. Sunset is a onereel, color and sound film that was originally conceived as Reel \#77 of Four Stars, Or, The Twenty-Four Hour Movie (****), and was commissioned by the de Menil family for a church restoration project. Sunset takes the idea of the Warholian unit to its logical extreme. Warhol extends the same treatment he has given to haircuts and the acts of eating and drinking to the natural phenomenon of the sunset: the very movements of the earth themselves are made to fit the parameters of the camera roll unit, are housed in the collection of "Warhols" of equal duration. The principle of the serial film likewise has its apotheosis in Four Stars, the existing footage for which comprises more than thirty reels that actually exceed the twenty-four hours of the title. ${ }^{\text {xxiv }}$ The project was conceptualized as a twenty-four hour film that would be screened only once in its entirety, and then broken down into approximately twelve feature-length segments, which Warhol planned to release commercially under different titles. ${ }^{\mathrm{xxv}}$ The film thus follows an organizing principle of modularity: a formal structure comprised of discrete units that can be separated, recombined, and recycled in a variety of ways. ${ }^{\text {xxvi }}$

Sunset begins with a white screen. Gradually, an image of a sun setting over a sandy expanse of land becomes identifiable. We come to realize that the bright sunlight, now beginning to fade, has bleached the image to create the first white screen. The camera has been rolling continuously and has not shifted from its opening framing. The image paradoxically becomes more intelligible as the light decreases; it is only when the sun has partially set that it ceases to over-expose the film so dramatically. Later in the film, the overly bright image gives way to an 
King, Homay, "Girl Interrupted," p. 22 of 27 under-exposed one. Here, the landscape once again recedes into abstract, Rothko-like bands of color, from dark gray to ruby glow. The film's subject — a sun setting over a beach — is visible and recognizable as such only in the brief interval when the light is neither too bright nor too dim. As in Empire (1964), the changes in illumination are so slow and faint that they are almost undetectable to the time-bound eye. Aside from a few panning motions on the part of the camera, the image looks like a projected still photograph or postcard. Paul Arthur has referred to Empire as "the longest establishing shot in history;" similarly, Sunset lingers on and extends a concluding image. ${ }^{\text {xxvii }}$ It also seems to offer a critique of the landscape genre analogous to that offered by Restaurant of the still life. That is, the addition of duration and movement troubles the impulse, present in many classical examples of landscape painting, toward the mastery and calculated division of space.

On the soundtrack, singer Nico recites poetry in voice-off. She speaks in a molassesslow, affectless monotone, occasionally repeating the previous words until finally reaching a complete sentence: "He walks. He walks along. He walks alone. He walks upon. He walks upon the sea." At these moments, it is as if the dialogue were on a loop tape. Like the subject of the poem, the words "walk" a few steps back for every step forward. The poem thus seems to do with language what Warhol does with serial images: its elements drag and repeat, but with small additions and differences inserted at each iteration. The poetic repetition partakes of a protracted, lingering temporality. Forward movement is only just barely discernible. The poem continues thus:

It is black...The light is white. The light...The night is always light....You are always bright...You are the light...You are the sound, you are the earth...You are 
King, Homay, "Girl Interrupted," p. 23 of 27

life...The earth stands still...You stand...You stand still...The earth stands for

life...You stand for life...You stand for light. You stand for the night.

The script for Sunset seems to posit a world in which every object can be brought into equivalence with anything else: "night" and "light" are equal to one another; "the earth" is made to stand for "life." The "you" to whom the poem is addressed is also made to stand in for "light," "sound," "earth," "life," and "night." The second-person structure of address, too, renders the film's audience equivalent to its own contents and elements. The repetition of the terms "always" and "standing still" furthermore suggests stasis, and a lack of transformation.

A sunset, of course, is the quintessential image of closure: in cinematic convention, it reads almost as the equivalent of "The End," or "And they lived happily ever after." But Warhol's Sunset ends abruptly, without warning or the gradual fade-out normally suggestive of eternal life and bliss. Instead, the sun plunges suddenly into darkness when the film leader snaps off the end of the reel as once again, Warhol adheres to his principle of using an entire roll of film. Just as we have acclimated ourselves to the unusually protracted pace of the film, the clock runs out, denying the moment of closure that would be provided by the sight of that last orange crescent dipping behind the horizon. This privileging of the camera roll's time over the eventtime of the sunset, I argue, invites us to view the film not as a grand finale, but as an experiment in perceptual open-endedness. The fact that Warhol was unsatisfied with the film and attempted to remake it several times, filming sunsets on both coasts, supports such a reading, in that it suggests that we ought to view this project as an ongoing series of trials and errors. These elements — the film's experimental ethos, its abrupt (lack of) conclusion, the multiple registrations, and the generative modularity suggested by its relation to the Four Stars project all work together to create a counter-reading of what might at first appear to be a repetitious, 
King, Homay, "Girl Interrupted," p. 24 of 27

deathly, and ending-obsessed temporality. Where one most expects to find a valorization of endings, one finds a visual manifestation of endurance, uneventfulness, a "to be continued" rather than a conclusion. The camera's infinite reserves of patience and delight in the face of uncertain rewards valorize progressive becoming over static being, and the not-yet over the already complete. Sunset testifies to the pleasures of the queerly unfinished.

Thanks to Charles Silver at MoMA for access to the film prints.

'Callie Angell, Andy Warhol Screen Tests: The Films of Andy Warhol Catalogue Raisonée, Volume One (New York: the Whitney Museum of Art, 2006). See also Callie Angell, "Andy Warhol: Outer and Inner Space," Program Notes for the Whitney Museum of American Art New American Film and Video Series 85 (October 15-November 29, 1998).

ii The versions of the films I discuss here are those in the collection of the Museum of Modern Art, New York, viewed at various times between March 2000 and February 2006.

iii See Andy Warhol and Pat Hackett, POPism: The Warhol Sixties (New York: Harcourt Brace Jovanovich, 1980): 49.

${ }^{\text {iv }}$ See, for example, the important scholarship in Pop Out: Queer Warhol, eds. Jennifer Doyle, Jonathan Flatley, and José Estaban Muñoz (Durham: Duke University Press, 1996); Juan A. Suárez, Bike Boys, Drag Queens, and Superstars: Avant-Garde, Mass Culture, and Gay Identities in the 1960s Underground Cinema (Bloomington: Indiana University Press, 1996); Douglas Crimp, "Mario Montez, For Shame," in Regarding Sedgwick: Essays on Queer Culture and Critical Theory, ed. Stephen M. Barber and David L. Clark (New York: Routledge, 2000); and Douglas Crimp, "Getting the Warhol We Deserve: Cultural Studies and Queer Culture." In[] visible Culture Issue Number 1 (Winter 1998).

"Thomas Waugh, "Cockteaser," in Pop Out: Queer Warhol, eds. Jennifer Doyle, Jonathan Flatley, and José Estaban Muñoz (Durham: Duke University Press, 1996): 52.

${ }^{\mathrm{vi}}$ In addition to the texts cited above, I also invoke Karen Beckman's reference to the importance of thinking "sex and sexual difference alongside innovation, form, and media" in studies of the avant-garde. Beckman, "Film Falls Apart: Crash, Semen, and Pop," Grey Room 12 (Summer 2003): 99, italics mine.

vii Judith Halberstam, In A Queer Time and Place: Transgender Bodies, Subcultural Lives (New York: New York University Press, 2005).

viii Parker Tyler, "Dragtime and Drugtime; Or, Film à la Warhol," Evergreen Review 11:46 (April 1967).

${ }^{\text {ix }}$ Elizabeth Freeman, "Packing History, Count(er)ing Generations," New Literary History 31 (2000): 728. I thank Bethany Schneider for pointing me to this essay.

"See for example Callie Angell, "Doubling the Screen: Andy Warhol's Outer and Inner Space," Millennium Film Journal 38 (Spring 2002): 19-33; and Roy Grundmann, "Masters of Ceremony: Media Demonstration as Performance in Three Instances of Expanded Cinema," The Velvet Light Trap 54 (Fall 2004): 48-64. 
${ }^{x i}$ Sigmund Freud, Three Essays on the Theory of Sexuality, trans. James Strachey (New York: Basic Books, 1962): 16. It is important to emphasize that for the Freud of Three Essays, perversion is not a pathology; rather, perversions are "constituents which are rarely absent from the sexual life of healthy people" (Freud, 26). For Freud, perversion refers to pleasure in any activities that are preliminary or marginal to heterosexual copulation for the purposes of reproduction, and activities pertaining to the pre-Oedipal (i.e., non-genital) phases and modes of sexuality.

xii See Callie Angell, “Andy Warhol, Filmmaker," The Andy Warhol Museum: An Inaugural Publication (Stuttgart: Cantz Publishers, 1994): 144 n. 39.

xiii See Victor Bockris, Warhol: The Biography (New York: Da Capo Press, 2003): 41. There is another Poor Little Rich Girl directed by Maurice Tourneur in 1917, starring Mary Pickford, but it is less likely that Warhol was referencing this earlier film.

xiv James defines "amateur" primarily in the sense described by Maya Deren in her 1959 essay "Amateur Versus Professional": "one who does something for the love of the thing rather than for economic reasons." David E. James, "Amateurs in the Industry Town: Stan Brakhage and Andy Warhol in Los Angeles," Grey Room 12 (Summer 2003): 81.

xv In "Mario Montez, For Shame" (cited above), Douglas Crimp provides a nuanced account of shaming exposure in Warhol's Screen Test \#2, in a reading that complicates accounts of Warhol as embodying a simply sadistic gaze. See also Hiram Perez' response to this piece, which calls attention to the racialized aspects of that film. Hiram Perez, "You Can Have My Brown Body and Eat It, Too!," Social Text 23 (Fall-Winter 2005).

${ }^{x v i}$ Warhol recounts the following incident which took place at the Barclay Hotel on a trip to Philadelphia for an opening at the ICA: "The management took one look at us and right there in the lobby started to determine each person's 'sex' by how long their hair was. They escorted Edie, giggling, to the 'boys' room' (she was wearing pants, so that'd clinched it) and they sent Gerard and Paul to the 'girls' room' because they both had longish curly hair" (POPism, 136). xvii Sedgwick's sister: "[Warhol] was androgynous, as Edie herself was. A kind of perverse Peter Pan" (Jean Stein, Edie: American Girl [New York: Grove Press, 1982]: 259).

${ }^{x v i i i}$ Restaurant was shot on an afternoon in May 1965. Sedgwick, Warhol, and several other Factory regulars did in fact go to Tangier and Paris in June of that year (POPism, 110-114). ${ }^{x i x}$ The name of the restaurant is L'Avventura, recalling Antonioni's 1960 film concerning the disappearance of a woman. Warhol was familiar with the films of Antonioni at least by 1967 , when he met the director and actress Monica Vitti at Cannes (POPism, 213).

${ }^{\mathrm{xx}}$ On the conventions of the Dutch still life, see for instance Norman Bryson, Looking at the Overlooked (Cambridge: Cambridge University Press, 1990), especially Chapter Two, "Rhopography;" and Hal Foster, "The Art of Fetishism: Notes on Dutch Still Life," in Fetishism as Cultural Discourse, eds. Emily Apter and William Pietz (Ithaca: Cornell University Press, 1993).

xxi Stephen Heath, "Narrative Space," Questions of Cinema (Bloomington: Indiana University Press, 1985).

xxii David McCabe, a young photographer Warhol assigned to document Factory life during 1965, plays the photographer in the film. See David McCabe, A Year in the Life of Andy Warhol (New York: Phaidon, 2003), which contains stills taken during the shoot.

xxiii Horse (1965), also written by Tavel, invokes the conventions of the Hollywood western in a similarly oblique way. 
xxiv Gregory Battcock has written about the effect of "telescoped" space in Kitchen as recalling the early Renaissance manner of Bouts, Campin, or Van Eyck. See "Four Films by Andy Warhol," in Andy Warhol: Film Factory, ed. Michael O'Pray (London: British Film Institute, 1989): 47.

${ }^{\mathrm{xxv}}$ Ronald Tavel, Kitchen (1965), script pages reproduced in Andy Warhol: Giant Size, a book conceived by Phaidon editors (New York: Phaidon, 2006): 321. See also http://ronaldtavel.com/home.htm, accessed September 30, 2007. Throughout this section, I quote dialogue from my transcriptions of the film rather than from Tavel's original script. I have endeavored to make a note when they differ, keeping in mind that film's sound quality is quite poor.

xxvi Tavel indicates that "for the most part, they do get through the screenplay," and that it was rehearsed for a solid week. He also notes that "the addition of David McCabe and René Ricard...was to help get through the mollusk-memoried Edie's fumblings with the script." Kitchen Screenplay (p. 3-4), http://ronald-tavel.com/home.htm, accessed September 30, 2007. xxvii Tavel's script indicates that Jo's line is "I always live my parts, too" (emphasis mine). xxviii This "breakdown" is in fact scripted by Tavel, and it prefigures a technique that Warhol would use in Chelsea Girls (1966): setting up conflicts between the players such that breaks in character were inevitable, and would form an integral part of the film. Similarly, in the filming of Vinyl (1965), Warhol "prevented the actors from learning their lines, so that the script had to be recited in an unnaturally stilted fashion from cue cards held up off camera" (Angell, "Andy Warhol, Filmmaker," 131).

${ }^{x x i x}$ Matthew Tinkcom, Working Like a Homosexual: Camp, Capital, Cinema (Durham: Duke University Press, 2002): 86.

${ }^{\mathrm{xxx}}$ Jean Laplanche provides the best gloss on Freud's early theory of the onset of sexuality as a traumatic, "precocious" seduction or "prematuration." See Jean Laplanche, New Foundations for Psychoanalysis, trans. David Macey (Oxford: Basil Blackwell, 1989).

xxxi Jonas Mekas, “ Notes After Reseeing the Movies of Andy Warhol," in Andy Warhol: Film Factory, ed. Michael O’Pray (London: British Film Institute, 1989): 41.

${ }^{x x x i i}$ Andy Warhol, The Philosophy of Andy Warhol (New York: Harvest, 1975): 93. xxxiii See, for example, Jack Smith's claims that Warhol stole his aesthetic from Flaming Creatures and Normal Love, quoted in the documentary film Jack Smith and the Destruction of Atlantis (Mary Jordan, 2006). Cary Loren concurs that Warhol's "use of non-actors came directly out of Smith" and that Smith "claimed he gave Warhol his first Bolex" (Branden W. Joseph, "Son of the Creature: An Interview with Cary Loren," Grey Room 12 [Summer 2003]: $125)$.

xxxiv Stephen Koch, Stargazer: Andy Warhol's World and His Films (New York: Praeger, 1974): 149.

${ }^{x x x v}$ See Richard L. Coe, “Andy Warhol and Associates," The Washington Post, April 26, 1967. Cited in Angell, "Andy Warhol, Filmmaker," 137. According to promotional materials in the collection of the Andy Warhol Museum in Pittsburgh, PA, a twenty-five hour version of the film was screened at the New Cinema Playhouse in New York City on December 16, 1967; and a ninety-minute version was screened at the University of St. Thomas on May 4, 1968.

${ }^{x x x v i}$ Lev Manovich identifies modularity as a defining feature of new media; in this sense, Warhol surely could be said to constitute one of its cinematic precursors. See Manovich, The Language of New Media (Cambridge, MA: The MIT Press, 2001). 
xxxvii "Freezing the opening moments of hundreds of standard Hollywood melodramas, "New York' is signified as a monument around which the clichéd 'eight million stories' may or may not be taking place" (Paul Arthur, "Flesh of Absence: Resighting the Warhol Catechism," in Andy Warhol: Film Factory, ed. Michael O'Pray [London: British Film Institute, 1989]: 149). Arthur's remarks suggest that Empire provides another example of a preliminary image that assumes the status of final product. 